Cuadernos de Pensamiento $\mathrm{N}^{\circ} 33$

Número monográfico sobre Karol Wojtyla/san Juan Pablo II

en el centenario de su nacimiento. Volumen 2.

Año: 2020

DOI: https://doi.org/10.51743/cpe.60

\title{
La superación de la autorreferencialidad del bien común en las fuentes wojtylianas
}

\section{Overcoming self-referentiality of the common good in wojtylian sources}

TERESA CID

Universidad CEU San Pablo

"No te dejes vencer por el mal, antes bien, vence al mal con el bien".

Rm 12, 21

RESUMEN: Karol Wojtyla nos ofrece una reflexión muy profunda y original sobre el bien común. La novedad consiste en el hecho de que el bien común se observa a la luz de aquel bien que es la comunión misma, la cual une a las personas entre sí. El bien de la comunión no es la suma de bienes dispersos cuya unidad se centra en los intereses particulares, sino el bien que causa la unión entre los hombres. Es el sentido principal de la trascendencia del bien. Analizaremos la amplia definición de bien común que se presenta en Gaudium et spes, para centrarnos después, siguiendo a nuestro autor, en el bien común concebido como el bien de vivir en comunión, es decir, el bien como guía de la vida humana. 
PALABRAS CLAVE: bien común, participación, vocación, trascendencia

ABSTRACT: Karol Wojtyla offers us a very deep and original reflection on the common good, whose novelty consists in the fact that the common good is observed in the light of that good that is communion itself, which unites people with each other. The good of communion is not the sum of dispersed goods whose unity is centred on particular interests; rather it is the good caused by the union between people. It is the main sense of the transcendence of good. In this paper, we will analyse the broad definition of the common good that is presented in Gaudium et spes, to focus later, following our author, on the common good conceived as the good of living in communion, that is, good as a guide to human life.

KEYWORDS: common good, participation, vocation, transcendence

\section{KAROL WOJTYLA, TESTIGO DE EXCEPCIÓN EN EL CONCILIO VATICANO II}

Cuando comenzó el Concilio Vaticano II, Karol Wojtyla tenía cuarenta y dos años, y llevaba cuatro como obispo auxiliar de Cracovia, su participación en el Concilio ${ }^{1}$ fue un acontecimiento decisivo para su existencia como obispo y una referencia constante durante todo su pontificado, así lo refleja en su testamento espiritual: «Estoy convencido de que durante mucho tiempo aún las nuevas generaciones podrán recurrir a las riquezas que este Concilio del siglo XX nos ha regalado. Como obispo que participó en el acontecimiento conciliar desde el primer día hasta el último, deseo confiar este gran patrimonio a todos los que están y estarán llamados a aplicarlo. Por mi parte, doy las gracias al eterno Pastor, que me ha permitido estar al servicio de esta grandísima causa a lo largo de todos los años de mi pontificado» ${ }^{2}$.

\footnotetext{
${ }^{1}$ Desde el primer día de su celebración hasta el último, es decir, del 11 de octubre de 1962 hasta el 8 de diciembre de 1965.

${ }^{2}$ El testamento de san Juan Pablo II. "Totus tuus ego sum": L'Osservatore Romano (ed. española) 37 (2005) 193-194, apunte añadido el 17 de marzo de 2000. Sobre la vida de san Juan Pablo II: A. RicCARDI, Juan Pablo II. La biografia, Ed. San Pablo, Madrid 2011; G. WeIGel, Biografia de Juan Pablo II. Testigo de esperanza, Planeta, Barcelona 1999; S.
} 
La participación en un Concilio, en este caso el de Trento, y el celo pastoral marcó también la vida de otro gran santo: «Cuando pienso - escribeen san Carlos Borromeo me conmueve la coincidencia de los hechos y quehaceres. Fue obispo de Milán en el siglo XVI, en el periodo del Concilio de Trento. A mí, el Señor me ha concedido ser obispo en el siglo XX, precisamente durante el Concilio Vaticano II, en vistas al cual se me ha confiado la misma tarea: su realización. Debo decir que en estos años de pontificado he pensado constantemente en la puesta en práctica del Concilio. Me ha sorprendido siempre esta coincidencia y en aquel obispo me fascinaba especialmente su enorme dedicación pastoral» ${ }^{3}$. Esa dedicación pastoral es una constante que le define a él también.

Se puede afirmar que Karol Wojtyla incorpora a su pensamiento todo el bagaje necesario para desarrollar su incansable actividad pastoral ${ }^{4}$, de hecho, el origen de sus estudios sobre el hombre es, como él mismo escribe: «en primer lugar, pastoral, y es desde el ángulo de lo pastoral cómo, en Amor y responsabilidad, formulé el concepto de norma personalista. Tal norma es la tentativa de traducir el mandamiento del amor al lenguaje de la ética filosófica. La persona es un ser para el que la única dimensión adecuada es el amor. Somos justos en lo que afecta a una persona cuando la amamos: esto vale para Dios y vale para el hombre. El amor por una persona excluye que se la pueda tratar como un objeto de disfrute» ${ }^{5}$.

Esta norma, ya presente en Kant, subraya que la persona no puede ser tratada como medio sino como fin. Sin embargo, Kant, que se opone al utilitarismo anglosajón, no interpreta de modo completo el mandamiento del amor que exige la afirmación de la persona por sí misma. La verdadera interpretación personalista del amor se encuentra en las palabras del Concilio, tal como destaca nuestro autor: «"el hombre — que en la tierra es la única criatura

DzIwISz, Una vida con Karol. Conversación con Gian Franco Svidercoschi, Esfera de los libros, Madrid 2008.

${ }^{3}$ JuAn PABlo II, ;Levantaos!, ;Vamos!, Plaza \& Janés, Barcelona 2004, 160.

${ }^{4}$ Se formó filosóficamente en el tomismo y en las corrientes personalistas, los filósofos del diálogo, y la fenomenología de Max Scheler. Ha recordado la importancia de estos filósofos que permiten un retorno a la metafísica desde una antropología integral en: JUAN PABLO II, Cruzando el umbral de la esperanza, Plaza \& Janés, Barcelona 1994, 56.

${ }^{5}$ JuAN PABLO II, Cruzando el umbral de la esperanza, o.c., 198-199. 
que Dios ha querido por sí misma- no puede encontrarse plenamente a sí misma si no es a través del don sincero de sí". Queda formulado con claridad el principio de afirmación de la persona por el simple hecho de ser persona; al mismo tiempo el texto conciliar subraya que lo más esencial del amor es el "sincero don de sí mismo". En este sentido la persona se realiza mediante el amor. Así pues, estos dos aspectos — la afirmación de la persona por sí misma y el don sincero de sí mismo - no solo no se excluyen mutuamente, sino que se confirman y se integran de modo recíproco. El hombre se afirma a sí mismo de manera más completa dándose» ${ }^{6}$.

En sus intervenciones en el Concilio sobresalen sus preocupaciones pastorales y su interés por la participación de los laicos en la misión de la Iglesia $^{7}$. Una de sus intervenciones en la tercera sesión (21-10-1964), sobre el entonces esquema XIII, provocó que se le incluyera en el equipo redactor: «Así pues, —escribe - ya durante la tercera sesión me encontré en el équipe

${ }^{6}$ JuAn PABlo II, Cruzando el umbral de la esperanza, Plaza \& Janés, Barcelona 1994, 199200. Cf. Introducción de P. FerRer en: Karol Wojtyla, Mi visión del hombre, Palabra, Madrid 1997, 7-22. La cita es de: Cons. pas. Gaudium et spes, 24.

${ }^{7}$ En las actas del Concilio se conservan ocho intervenciones orales y dieciséis escritas. Cf. J.L. LoRDA, Antropología del Concilio Vaticano II a Juan Pablo II, Palabra, Madrid 1996, 105-106; S. MAdRIGAL, Tríptico conciliar: relato - misterio - espíritu del Vaticano II, Sal terrae, Santander 2012, 81-159. El texto en latín con la traducción castellana de sus intervenciones orales y escritas en las sesiones del Concilio ha sido cuidadosamente editado por G. Richi, Karol Wojtyla: un estilo conciliar en el Concilio Vaticano II, Studia Theologica Matritensia 16 - San Dámaso, Madrid 2010, especialmente, "Intervenciones de Karol Wojtyla sobre el esquema XXIII”, pp. 301-433. En el estudio preliminar que acompaña las intervenciones de Wojtyla en el aula conciliar, G. Richi sintetiza las claves hermenéuticas más significativas del Vaticano II: el evento del Concilio, su índole pastoral, la eclesiología teológica y cristocéntrica, el personalismo cristiano, la fuerza del testimonio y de la profecía. Un buen complemento es el volumen en el que se recogen las homilías y discursos de Karol Wojtyla durante su época de arzobispo de Cracovia, cuyo hilo conductor es la celebración y desarrollo del Concilio Vaticano II: G. RichI (ed.), Karol Wojtyla. La renovación de la Iglesia y del mundo. Reflexiones sobre el Concilio Vaticano II, BAC - Univ. San Dámaso, Madrid 2016. Véase también: G. MArengo, Giovanni Paolo II e il Concilio. Una sfida e un compito, Cantagalli, Siena 2011; C. Pozo, "Juan Pablo II y el Concilio Vaticano II”, en Scripta Theologica, 20 (1988) 405-437. H.J. ANTÚNEZ, Karol Wojtyla y Gaudium et spes. Historia de las intervenciones de Juan Pablo II en la elaboración de la Constitución pastoral, Thesis ad Doctorandum in Sacra Theologia partim edita, Pontificia Universitas Sanctae Crucis, Roma 2005, 80-81. 
que preparaba el llamado esquema XIII, el documento que se convertiría luego en la Constitución pastoral Gaudium et spes, pude de este modo participar en los trabajos extremadamente interesantes de este grupo, compuesto por representantes de la Comisión teológica y del Apostolado de los laicos. Permanece vivo en mi memoria el recuerdo del encuentro de Ariccia, en enero de $1965 »^{8}$.

Durante su participación en la nueva redacción del esquema XIII de la Gaudium et spes, hizo esta propuesta muy conocida por los estudiosos: "Ya que el esquema quiere tener sobre todo un carácter profundamente pastoral, es bueno que se le dé la mayor importancia a la persona humana, tanto en sí misma como en la comunidad (en la vida social) y en general. En efecto, toda la solicitud pastoral presupone la persona humana, ya sea como sujeto [...] ya sea como objeto» ${ }^{9}$. En la alocución aborda fundamentalmente dos argumentos: el primero, sobre la "índole pastoral" del esquema, que justifica la atención principal que recibe, en la primera parte del esquema, la persona humana, considerada según la integridad de su vocación. Ahora bien, la pastoralidad sugiere, además, que el texto refleje adecuadamente el horizonte salvífico pues toda la solicitud pastoral presupone la obra de redención realizada en la cruz. Insiste en que la obra de la Iglesia no puede ser reducida al servicio de la edificación del mundo, pues el mayor servicio de la Iglesia es el servicio de la salvación eterna. Subraya que el elemento de la crítica del mundo es tan esencial como la actitud positiva hacia el esfuerzo humano.

La idea de la trascendencia de la salvación eterna relativa a todo fin mundano es característica de su pensamiento. Esta idea de trascendencia permite comprender como la redención puede habitar la historia del hombre

${ }^{8}$ JuAn PABlo II, Cruzando el umbral de la esperanza, Plaza \& Janés, Barcelona 1994, 165.

${ }^{9}$ K. Wojtyla, Intervención oral del 28 de septiembre de 1965, en la $137^{\text {a }}$ Congregación General, en: G. RichI, Karol Wojtyla: un estilo conciliar en el Concilio Vaticano II, Studia Theologica Matritensia 16 - San Dámaso, Madrid 2010, 409. Cf. G. WeIGEL, Biografía de Juan Pablo II: testigo de esperanza, Plaza \& Janés, Barcelona 1999, 235-236. La Constitución pastoral Gaudium et spes, se promulga el 7 de diciembre de 1965, el día anterior a la clausura del Concilio Vaticano II. Cf. F. GIL Hellín, Constitutio Pastoralis de Ecclesia in mundo huius emporis Gaudium et spes. Concilii Vaticani II Synopsis, Pontificia Universitas Sanctae Crucis - Libreria Editrice Vaticana, Città del Vaticano 2003. 
y, sin embargo, ser siempre irreductible a ella ${ }^{10}$, e ilumina el sentido más profundo del bien común. La segunda parte de la alocución está dedicada al tema del ateísmo y su relación con la libertad religiosa. Propone distinguir el ateísmo fruto de la decisión personal, del ateísmo impuesto coercitivamente, que constituye una ofensa contra la ley natural. Afirma que no es suficiente considerar el ateísmo como negación de Dios, el problema es específicamente humano: el hombre ateo está persuadido de su soledad final, escatológica. Se entiende entonces que el hombre responda a esta soledad vinculada a la negación de la inmortalidad buscando un sucedáneo de eternidad en el colectivismo ${ }^{11}$.

Tras la clausura del Vaticano II, al regresar a Polonia organizó la celebración de un sínodo diocesano con amplia participación de sacerdotes y laicos. Sus trabajos se inician en 1972 y fueron clausurados por él ya como papa en 1979. Sobre la base de su experiencia conciliar y con vistas al sínodo, publicó La renovación en sus fuentes. Sobre la aplicación del Concilio Vaticano II (1972), una reflexión sistemática que recogía el núcleo de las enseñanzas del Concilio. Al comenzar la tercera parte del libro anota: «En conformidad con la situación del presente estudio, no tratamos de dar una explicación de la doctrina del Vaticano II "como tal", sino más bien buscar en todo el magisterio conciliar la respuesta a las preguntas de carácter existencial: ¿Qué significa ser creyente, ser cristiano, estar en la Iglesia?» ${ }^{12}$. A su juicio, el Concilio al responder a estos interrogantes existenciales en los que estaba implícito el problema central del Concilio, «Iglesia, ¿qué dices de ti mis$m a ?^{13} \gg$, ha propiciado un verdadero enriquecimiento de la fe. Para el arzobispo de Cracovia la participación de todos los cristianos en la triple misión de Cristo, es decir, la dimensión profética, sacerdotal y real, era la clave de

${ }^{10}$ Cf. R. Buttiglione, El pensamiento de Karol Wojtyla, Encuentro, Madrid 1992, 233.

${ }^{11}$ Cf. G. Richi, Karol Wojtyla: un estilo conciliar en el Concilio Vaticano II, o.c., 407. A. WILDER, "Community of persons in the Thought of Karol Wojtyla", en Angelicum, 56 (1979) 211-244, especialmente 243-244.

${ }^{12}$ K. WojtYla, La renovación en sus fuentes. Sobre la aplicación del Concilio Vaticano II, BAC, Madrid 1982, 163.

${ }^{13}$ Es la célebre pregunta que el cardenal Suenens propuso el 4 de diciembre de 1962 como finalidad del Concilio. Cf. G. Richi (ed.), Estudio preliminar, Karol Wojtyla. La renovación de la Iglesia y del mundo. Reflexiones sobre el Concilio Vaticano II, o.c., 51. 
compresión de la doctrina conciliar. Esta toma de conciencia debía ir acompañada de una responsabilidad en la vida real y cotidiana.

Siguiendo la estela del Concilio, en su primera encíclica, Redemptor hominis (1979), el misterio de la redención está visto con los ojos de la gran renovación del hombre y de todo lo que es humano, propuesto por el Concilio, especialmente en la Gaudium et spes ${ }^{14}$. La encíclica recuerda el número 22 de Gaudium et spes, como lo recuerda también la famosa homilía de inicio del pontificado: «Hermanos y hermanas, no tengáis miedo de acoger a Cristo y de aceptar su potestad, Ayudad al Papa y a todos los que quieren servir a Cristo y, con la potestad de Cristo, servir al hombre y a la humanidad entera, ¡No temáis!, ¡Abrid, más aun, abrid de par en par las puertas a Cristo! [...]. Cristo conoce "lo que hay dentro del hombre", ¡sólo Él lo conoce!”». En la carta apostólica Novo millennio ineunte (2000) con motivo de la clausura de la celebración del Año jubilar, nos recuerda que el Vaticano II es «la gran gracia de la que la Iglesia se ha beneficiado en el siglo XX, una brújula segura para orientarnos en el camino del tercer milenio» ${ }^{15}$.

\section{LOS NÚMEROS 22 Y 24 DE GAUDIUM ET SPES: LA VOCACIÓN AL AMOR}

En el libro La renovación en sus fuentes, intenta recoger lo más importante de todos los documentos del Concilio y cita multitud de textos, pero ya se anuncia la importancia que daba a dos números de Gaudium et spes que luego haría famosos a lo largo de su pontificado; entre 1978 y 2003, citó 225 veces el primer párrafo del número 22 de Gaudium et spes. También citó innumerables veces algunas frases del número 24. En el primero, Cristo revela el hombre al propio hombre y le descubre la grandeza de su vocación, en el segundo, le muestra cómo vivirla, en la entrega sincera de sí mismo: «La constitución pastoral Gaudium et spes — escribe - que planteaba los interrogantes fundamentales a los que toda persona está llamada a responder, nos repite hoy también a nosotros unas palabras que no han perdido su actua-

${ }^{14}$ Cf. JuAn Pablo II, Cruzando el umbral de la esperanza, o.c., 65-66.

${ }^{15}$ JUAN PABLO II, carta apostólica Novo millennio ineunte, 86. 
lidad: "El misterio del hombre solo se esclarece en el misterio del Verbo encarnado" (n. 22). Son palabras que aprecio mucho y que he querido volver a proponer en los pasajes fundamentales de mi magisterio» ${ }^{16}$.

En la encíclica Fides et ratio, resumía: «No puedo olvidar [...] un capítulo de la Constitución Gaudium et spes, es casi un compendio de antropología bíblica $[\ldots]$ que he citado en mi primera encíclica Redemptor hominis y que representa uno de los puntos de referencia constante de mi enseñanza: "Realmente, el misterio del hombre solo se esclarece en el misterio del Verbo encarnado. Pues Adán, el primer hombre, era figura del que había de venir, es decir, de Cristo, el Señor. Cristo, el nuevo Adán, en la misma revelación del misterio del Padre y de su amor, manifiesta plenamente el hombre al propio hombre y le descubre la grandeza de su vocación"17.

El Concilio Vaticano II, en la constitución Gaudium et spes, había afirmado ya la centralidad de la vocación para la antropología cristiana: "La razón más profunda de la dignidad humana, está en la vocación del hombre a la comunión de Dios. Ya desde su nacimiento es invitado el hombre al diálogo con Dios: pues, si existe, es porque, habiéndole creado Dios por amor, por amor le conserva siempre, y no vivirá plenamente conforme a la verdad, si no reconoce libremente este amor y si no se entrega a su Creador" ${ }^{\prime 18}$.

En profunda continuidad con esta constitución, Juan Pablo II, acuña el concepto de vocación al amor para sintetizar su comprensión de la llamada de Dios a cada hombre ${ }^{19}$. La articulación interna de su dinámica la explica mediante la unión profunda que establece entre los números 22 y 24 de Gaudium et spes: el primero se refiere a la revelación de la vocación del hombre en Cristo, que requiere una respuesta por parte del hombre, que es lo que

16 JuAn PABlo II, Discurso de clausura del Congreso Internacional sobre la aplicación del Concilio Ecuménico Vaticano II, 27 de febrero de 2002, 8; J. L. LoRDA, "Teología del siglo XX”, revista Palabra, nov 2015, 60; G. WeIGEL, Biografia de Juan Pablo II: testigo de esperanza, o.c., 236-237.

${ }^{17}$ JuAn PABLo II, carta enc. Fides et ratio, 60. Cita Guadium et spes, 22.

${ }^{18}$ Concilio Vaticano II, Const. past. Gaudium et spes, 19.

19 Juan Pablo II, Redemptor hominis, 8, 10, 13; Familiaris consortio, 11; Mulieris dignitatem, 7; Evangelium vitae, 29-30, 76; Tertio millennio adveniente, 4-8; Dives in misericordia, 1; Dominum et vivificantem, 10, 59. Ver al respecto: T. CID, Persona, Amor y vocación. Dar un nombre al amor o la luz del sí, Edicep, Valencia 2009, 101-134. 
expresa el número $24^{20}$. Solo Cristo con su humanidad revela hasta el fondo el misterio del hombre. Cristo murió por todos y la vocación última del hombre es realmente una sola, es decir, la vocación divina, hasta tal punto que «al margen del Evangelio, el hombre se queda en un dramático interrogante sin respuesta. Porque la respuesta apropiada a la pregunta sobre el hombre es Cristo, el Redemptor hominis» ${ }^{21}$.

Juan Pablo II ha sabido comprender la conjunción de los dos textos - GS 22 y 24 - en una original síntesis que configura la vocación originaria al amor, que ya presentó de forma articulada en su primera encíclica: «El hombre no puede vivir sin amor. Él permanece para sí mismo un ser incomprensible, su vida está privada de sentido si no se le revela el amor, si no se encuentra con el amor, si no lo experimenta y lo hace propio, si no participa de él vivamente. Por esto precisamente, Cristo Redentor, como se ha dicho anteriormente, revela plenamente el hombre al mismo hombre» ${ }^{22}$.

En esta vocación al amor entendida en clave de revelación personal, el amor es para el hombre, en primer lugar, una respuesta y la inserción en una historia de amor que le precede y que debe ser el camino de la propia realización. Este modo de presentarla permite ver el valor singular del amor esponsal para la revelación del amor divino. Esta conjunción específica del momento natural del amor y de la libertad que llega a la expresión de toda la persona, es el fundamento que permite hablar del amor como una vocación ${ }^{23}$.

${ }^{20}$ Cf. J.J. PÉREz-SobA, El corazón de la familia, Publicaciones Facultad de Teología «San Dámaso», Madrid 2006, 163 y ss. ID., «Juan Pablo II y la familia», en Cuadernos de pensamiento 17, Fundación Universitaria Española, Madrid 2005, 221-226.

${ }^{21}$ JuAn PABlo II, Memoria e identidad, La esfera de los libros, Madrid 2005, 142-143.

22 JUAN PABLO II, carta enc. Redemptor hominis, 10.

${ }^{23}$ Cf. K. Wojtyla, Amor y responsabilidad. Estudio de moral sexual, Razón y fe, Madrid 1978, 291-295; JUAN PABLo II, La vida como vocación, Mensaje para la Jornada Mundial de oración por las vocaciones, 6 mayo 2001: «La palabra vocación cualifica muy bien las relaciones de Dios con cada ser humano en la libertad del amor, porque 'cada vida es vocación'». La cita es de PABLO VI: Populorum progressio 15; BENEDICTO XVI, carta enc. Caritas in veritate, $\mathrm{n}$. 1 . Una síntesis de la dinámica de la vocación originaria al amor nos la ofrece en el siguiente texto de la exhortación apostólica Familiaris consortio, 14: «Dios ha creado al hombre a su imagen y semejanza: llamándolo a la existencia por amor, lo ha llamado al mismo tiempo al amor. Dios es amor y vive en sí mismo un misterio de comunión personal de amor. Creándola a su imagen y semejanza y conservándola continuamente en el 
Es el amor en su dinámica y su valor personal el que sirve de hilo conductor de toda la existencia humana y del relieve que alcanzan las distintas realidades que la conforman. La mención de la vocación es la que da unidad personal, la propia de la identidad, a todas las otras realidades que están presentes en ella ${ }^{24}$. De ahí que el proceso de revelación de la persona sea al mismo tiempo un proceso de construcción personal. Es la consecuencia de la categoría de la vocación ${ }^{25}$. El amor no es entonces un mero impulso cósmico o una actitud hacia otro, sino una luz que nos permite interpretar nuestra vida en las circunstancias más diversas. De esta manera, el amor no es el riesgo de una iniciativa - Dios nos ha amado primero-, sino la respuesta a una llamada que configura una vocación ${ }^{26}$.

Bajo el aspecto de la vocación todos los estados y profesiones constituyen caminos distintos de la vida humana que conducen a un único fin: «La conciencia de la vocación es un bien enorme, pues con su gracia el hombre encuentra su finalidad y el orden en sí mismo y en el mundo» ${ }^{27}$. El hombre ha sido creado para realizar su vocación personal en la verdad de la actuación $^{28}$. Una vocación que el hombre descubre en la medida en la que se realiza en su actuación. Éste es el modo como el amor puede ser el contenido de la vocación del hombre ${ }^{29}$.

ser, Dios inscribe en la humanidad del hombre y de la mujer la vocación y consiguientemente la capacidad y la responsabilidad del amor y de la comunión. El amor es, por tanto, la vocación fundamental e innata de todo ser humano».

${ }^{24}$ Cf. J.J. PÉREZ-SOBA, «La esencia del amor: un análisis ético», en Cuadernos de pensamiento 20, Fundación Universitaria Española, Madrid 2008, 11-33; ID., «La caridad: luz que ilumina a todo hombre», en Cuadernos de pensamiento 18, Fundación Universitaria Española, Madrid 2007, 13-31.

${ }^{25}$ Cf. L. Melina- J. NoriegA- J.J. PÉReZ-SoBA, Caminar a la luz del amor Los fundamentos de la moral cristiana, Palabra, Madrid 2007, 334.

${ }^{26}$ Cf. JuAn PABLO II, carta enc. Veritatis splendor, 24.

${ }^{27}$ K. WojtYLA, Intervención oral del 21 de octubre de 1964, en G. Richi, Karol Wojtyla: un estilo conciliar en el Concilio Vaticano II, o.c., 351.

${ }^{28}$ Cf. L. MelinA- J. Noriega- J.J. PÉREZ-SobA, La plenitud del obrar cristiano, o.c., 30.

${ }^{29}$ Cf. J.J. PÉREZ-SoBA, «Persona, amor, y moral», en Cuadernos de Pensamiento 16, Fundación Universitaria Española, Madrid 2004, 345-365; E. MouniER, "Manifiesto al servicio del personalismo", en M. GARCíA-BARó (dir.), El personalismo. Antología esencial, Sígueme, Salamanca 2002. 
El conjunto de todas las realidades presentadas como el bien pleno del hombre se puede expresar en su integridad por medio de la categoría de la vocación, una llamada que precede al hombre y que se le expresa como una elección divina que debe saber realizar en su propia vida. Es de un valor tan grande que solo así se defiende adecuadamente el valor insustituible de cada persona $^{30}$. Desde esta perspectiva de la vocación al amor, se puede afrontar de un modo original la cuestión del bien común, recuperando la experiencia primordial, la experiencia de que es bueno vivir en común con otros. La trascendencia de un amor que nos precede ilumina el significado de la libertad que ha de dirigirse ahora a la promoción del bien común. A continuación, analizaremos la amplia definición de bien común que se presenta en Gaudium et spes, para centrarnos después en el bien común concebido como el bien de vivir en comunión, es decir, el bien como guía de la vida humana.

\section{EL BIEN COMÚN EN LA GAUDIUM ET SPES: LA VÍA INSTITUCIONAL}

El concepto de bien común ocupó un lugar relevante en la filosofía política clásica $^{31}$, y es uno de los conceptos básicos del pensamiento social cristiano, sin embargo, la expresión fue vaciándose de contenido a partir de los planteamientos políticos y morales de la modernidad hasta que cayó en desuso. Ha vuelto a reaparecer aunque con sentidos muy distintos. En primer lugar,

${ }^{30}$ Es el argumento principal de J. MARITAIN, La personne et le bien commun, Desclée de Brouwer, Bruselas, 1946. (E.C., Éditions Universitaires- Éditons Saint-Paul, FribourgParis 1990, vol. IX, 167-237).

${ }^{31}$ PLATÓN, Las leyes, 875a: «El auténtico arte político no debe preocuparse del bien privado, sino del bien común, pues el bien común estrecha los vínculos ciudadanos, mientras que el bien privado los disuelve, y tanto el bien particular como el bien común salen ganando si este segundo está sólidamente garantizado con preferencia al otro». ARISTÓTELES, Política, I, 1252b30; CicERÓn, Sobre la República, lib. 1, cap. 25, Obras, Edaf, Madrid, 1977, 14041405; SAn Agustín, La ciudad de Dios, lib. 2, cap. 21, n. 2, Obras completas de San Agustín, 116, BAC, Madrid, $1964^{2}, 102$. Quien acuñó el concepto fue SANTO TOMÁs DE AQUINO, Summa Theologica,I-II, q. 19, a. 10; y los clásicos españoles del derecho natural: Francisco de Vitoria, Domingo de Soto, y Francisco Suárez. Cf. T. Gelardo Rodríguez, La política y el bien común, Navarra Gráfica Ediciones, Pamplona 2005. 
nos encontramos con la dificultad que supone hablar del bien, el bien común es ante todo "bien", y el siglo XX se ha caracterizado por una progresiva marginación de la categoría del "bien" en la ética, mediante la sustitución por otros términos como el "valor", la "justicia", sobre los que se intenta fundar la convivencia humana, sin duda, ello se debe a la dimensión metafísica que contiene en sí misma la categoría del bien, que remite a la existencia de un Bien supremo, Dios ${ }^{32}$.

En efecto, desde Hobbes a Rawls ${ }^{33}$, para el pensamiento político moderno y contemporáneo, el objetivo no es tanto la realización del bien humano cuanto el logro de la paz social en la que se respeten los derechos individuales. La sociedad se debe basar fundamentalmente en la justicia y la libertad, lo que implica que se debe ocupar sobre todo de preservar básicamente la capacidad autónoma de elección de los sujetos independientemente de cuál sea su concepción del bien y, en todo caso, establecer reglas para armonizar los bienes discrepantes. Se da así primacía a los sistemas procedimentales en el orden político, tratando de determinar la estructura social por la sola justicia. Una justicia que se autoconstituye a sí misma mediante un procedimiento acordado, de tal modo, que ni siquiera se hace una referencia sustantiva al bien para poder determinar los contenidos concretos de la justicia.

Tanto el liberalismo - al anteponer los intereses individuales a los comunes - como el marxismo - al negar la individualidad - son incapaces de advertir que el bien común es una dimensión fundamental de la vida en sociedad. El bien común es considerado en su elemento formal e institucional, como el conjunto de instituciones y estructuras sociales que permiten coordinar la acción libre de los ciudadanos en aras de sus particulares fines y concepciones del bien. El bien común, en este sentido, está identificado simplemente con el mantenimiento de un orden social de libertad, como valor y fin último, pero sin referencia a la verdad del bien humano ${ }^{34}$.

\footnotetext{
${ }^{32}$ Cf. C. CARdona, Metafisica del bien común, Madrid 1966.

${ }^{33}$ J. RAwls, A Theory of Justice, Harvard University Press, Cambridge Mass. 1971 (trad. esp.: Una teoría de la justicia, Fondo de Cultura Económica, México 1979). Se ha convertido en una referencia obligada en la filosofía política contemporánea, máximo representante del pensamiento liberal.

${ }^{34}$ Cf. J. BALlesteros, “Del bien común al bien de la comunión”, en R. Rubio DE URQUía, J.
} 
Esta concepción del bien común, de naturaleza formal e instrumental, se ha plasmado en el Estado de Derecho, el imperio de la ley y la búsqueda de la paz social a través del consenso. De ella se hace eco de alguna forma el magisterio de la Iglesia, como muestran algunas de las definiciones del bien común que encontramos en el mismo. La famosa definición de Juan XXIII ${ }^{35}$ — recogida después casi literalmente en la Gaudium et spes- es en realidad una formulación simplificada de la propuesta por Pío XII en el radiomensaje navideño de $1942^{36}$. Los padres conciliares definen el bien común como "el conjunto de condiciones de la vida social que hacen posible a las asociaciones y a cada uno de sus miembros el logro más pleno y más fácil de su propia perfección" ${ }^{37}$. Esta definición incluye el ordenamiento jurídico y las instituciones que lo garantizan; las instituciones de enseñanza y atención sanitaria, las comunicaciones, las instituciones de previsión social, el desarrollo de iniciativas culturales, deportivas y religiosas, etc. Y va más allá, al negar que el bien común se pueda reducir a un acuerdo instrumental sobre las normas de cooperación mutua, ajeno a los fines y los valores que definen la verdad el bien humano ${ }^{38}$.

Sin duda, es una definición que puede ser aceptada por cualquier persona, independientemente de su credo o ideales, pues se refiere a la forma de organizar la sociedad, a las instituciones para regular la convivencia, leyes, costumbre, es decir, señala la vía institucional, sin embargo, el bien común

PÉrez-SobA (eds.), La doctrina social de la Iglesia. Estudios a la luz de la encíclica Caritas in veritate, BAC, Madrid 2014, 283-304.

35 JUAN XXIII, carta enc. Mater et magistra, 15-5-1961, 65: «El bien común abarca todo un conjunto de condiciones sociales que permiten a los ciudadanos el desarrollo expedito y pleno de su propia perfección».

${ }^{36}$ Pío XII, Radiomensaje de Navidad, Con sempre nuova freschezza, (24-12-1942): «Entendemos por bien común aquellas condiciones externas que son necesarias al conjunto de los ciudadanos para el desarrollo de sus cualidades y de sus oficios, de su vida material, intelectual y religiosa».

${ }^{37}$ Cons. pas. Gaudium et spes, 26; en el número 74, se indica que el bien común es el fin de la actividad política y "abarca el conjunto de aquellas condiciones de la vida social con las cuales los hombres, familias y las asociaciones pueden lograr con mayor plenitud y facilidad su propia perfección". Se analiza en: A. HERRERA Oria (dir) Comentarios a la Constitución Gaudium et spes sobre la Iglesia en el mundo de hoy, BAC, Madrid 1968, 218-266.

${ }^{38} \mathrm{Cf}$. BenEDICTO XVI, carta enc. Caritas in veritate, 7. 
no se puede agotar en el contexto institucional, en realidad, esta definición no es más que una primera y vasta acepción del bien común. La organización social se tiene que poner al servicio de las personas, de su desarrollo, y lo hace apoyando las asociaciones, grupos, comunidades, para que sean el lugar en el que podamos sacar lo mejor de nosotros mismos.

El bien común está al servicio del desarrollo integral de las personas. Esto significa que el bien común no se refiere solo a la manera de organizarnos sino al objetivo final que buscamos y, por tanto, ha de ser definido en referencia a las personas. Las personas, en cuanto seres esencialmente sociales y morales, tienen una aspiración común a una convivencia bue$\mathrm{na}^{39}$. En este sentido, el bien se sitúa en el orden de los fines y es el principio de toda acción social. Desde los clásicos, el fin propio de la sociedad es la búsqueda de un bien social, ese era el sentido de la comunidad, la búsqueda del bien común.

A pesar de la semejanza de la definición conciliar con la concepción liberal del bien común, en ella aparece un elemento esencial que rechazan las teorías liberales, como es la referencia a la perfección humana, que no se limita a la vida material, económica, política, y cultural, pues tiene una dimensión trascedente. Se subraya que el conjunto de la vida social ha de estar orientado a la perfección de "cada" persona y de "toda" la persona, esto es, al desarrollo humano integral y solidario ${ }^{40}$. Es decir, la vía institucional de la caridad debe estar al servicio del desarrollo humano integral. El desarrollo como vocación permite referirlo, en primer lugar, a las personas, y no solamente a la multiplicación de las cosas. Se trata, como afirma el Concilio, no tanto de «tener más» cuanto de «ser más» ${ }^{41}$. Sin embargo, las concepciones claramente restrictivas de la realidad humana transforman el bien común en

\footnotetext{
${ }^{39}$ Cons. pas. Gaudium et spes, 25: «La persona humana, por su misma naturaleza, tiene absoluta necesidad de la vida social. La vida social no es, pues, para el hombre sobrecarga accidental».

${ }^{40}$ Cf. J. Ballesteros, La justicia social en el Magisterio de la Iglesia, Madrid 2008, 192-194.

${ }^{41}$ Cfr. Concilio Vaticano II, Const. past. Gaudium et spes, 35; Pablo VI, Discurso al Cuerpo diplomático, 7 enero 1965; PABLO VI, carta enc. Populorum progressio, 14; JUAN PABLO II, Redemptor hominis, 16.
} 
un simple bienestar socioeconómico, carente de toda referencia trascendente y vacío de su más profunda razón de ser.

El bien común, en cambio, tiene también una dimensión trascendente, porque Dios es el fin último de sus criaturas ${ }^{42}$. Posee una moralidad intrínseca, no es un conjunto de ventajas y utilidades ${ }^{43}$, sino que implica aspiración a la rectitud de vida de las personas y hace posible la comunión en el vivir, de ahí que éste exija el desarrollo de las virtudes de los miembros de la comunidad. Si el bien común ha de estar al servicio del desarrollo humano integral es evidente que ha de trascender los límites de los ámbitos socioeconómico y jurídico-político en los que a menudo había sido confinado, es necesario reconocer su dimensión trascendente.

De ahí la importancia de la dimensión moral del bien común, en este sentido, es decisiva la consideración de la cuestión del bien común desde la perspectiva de la persona que actúa, porque sólo a través de la misma el hombre, llamado a la comunión, se abre a los demás y, en última instancia, se perfecciona a sí mismo y puede alcanzar su desarrollo integral ${ }^{44}$. El bien común no es la simple suma de los intereses particulares, implica su valoración y armonización, hecha según una equilibrada jerarquía de valores y, en última instancia, según una exacta comprensión de la dignidad y de los derechos de la persona. Siendo de todos y cada uno permanece común porque es indivisible y solo juntos es posible alcanzarlo. Es el bien de cada uno considerado solidario del bien de los demás ${ }^{45}$. Si el actuar moral del individuo se realiza en el cumplimiento del bien, el actuar social alcanza su plenitud en la realización del bien común. El bien común se puede considerar entonces como la dimensión social y comunitaria del bien moral.

\footnotetext{
42 Juan Pablo II, Mensaje para la Jornada Mundial de la paz (1 enero 2005), 5; cart. enc. Centesimus_annus, 41.

${ }^{43}$ Cf. J. MARitain, La persona y el bien común, Club de Lectores, Buenos Aires 1968.

${ }^{44}$ Cf. J. DE Dios Larrú Ramos, "La verdad de la caridad y el bien común", en R. RUBio DE URQUía, J. PÉREZ-SobA (eds.), La doctrina social de la Iglesia. Estudios a la luz de la encíclica Caritas in veritate, BAC, Madrid 2014, 305-324.

${ }^{45}$ Cf. JuAn PABLo II, carta enc. Centesimus annus, 47.
} 


\section{EL BIEN COMO GUÍA DE LA VIDA HUMANA: EL BIEN EXCELENTE Y EL BIEN COMÚN}

El bien, en cuanto realidad dinámica, tiene que ver con la atracción que sufre el sujeto por parte de un objeto. Es lo que expresa la conocida afirmación aristotélica: "el bien es lo que todos apetecen"46. La segunda realidad que se esconde en el bien es entonces, una llamada. Esto es, en el apetecer no se puede ver lo específico del bien moral, incluso a pesar de comprender que el apetecer del hombre sea racional y voluntario. En cambio, la llamada a la libertad por parte del bien nos habla de un fin en el que la misma persona está implicada.

El bien es una realidad que no sólo atrae, sino que interpela a la libertad humana. Este modo específico de bien que sólo el hombre desarrolla está unido a su libertad en relación a su dimensión de imagen de Dios. Esta bondad, preanunciada en el apetito, necesita ahora una determinación personal en una dimensión dialógica que se le aparece como intrínseca ${ }^{47}$. Esta llamada, más allá de la conveniencia, surge de una primera presencia afectiva y sólo puede calificarse adecuadamente como $a_{m o r}{ }^{48}$. Es él el que tiene su propia racionalidad y apunta a un bien que sólo le corresponde al hombre y que sólo puede alcanzar si ama con todo su corazón. Es aquí donde la dimensión de comunión, un bien siempre mayor que el bien propio y la capacidad de acción, que se aplica de modo pleno al concepto de imagen ${ }^{49}$, es una aportación auténticamente preciosa para ver la dimensión esencialmente comunitaria del bien, que podemos llamar realmente "bien común".

\footnotetext{
${ }^{46}$ ARISTÓTELES, Ética a Nicómaco, 1. 1, c. 1, 1094a3. Critica esta definición por entrar en una circularidad basada en definir la potencia por el objeto y el objeto por la potencia y, además, en este esquema la libertad como "facultad de todo el hombre" no aparece explícita: S. TomÁs de Aquino, In II Sent., d. 24, q. 1, a. 2, ad 1: "dicitur [liberum arbitrium] non pars animae, sed tota anima".

${ }^{47}$ Cf. H.U. von Balthasar, Las nueve tesis, tesis 5, en Comisión TeOlógica InTERnATIONAL, Documentos (1969-1996), BAC, Madrid 1998, 94.

${ }^{48}$ Una explicación en: L. MeLinA, "El amor: encuentro con un acontecimiento", en L. MELINA -C. ANDERSON (eds.), La vía del amor. Reflexiones sobre la encíclica Deus caritas est de Benedicto XVI, Monte Carmelo -Instituto Juan Pablo II, Burgos 2006, 1-12.

49 JuAn PABlo II, Hombre y mujer lo creó, (Catequesis 9, 14-11-1979), Cristiandad, Madrid 2000, 91-96.
} 
Lo importante es que no se percibe el bien de la comunión a modo de una suma de bienes dispersos cuya unidad se centra en los intereses particulares, sino como los bienes que causan la unión entre los hombres y en relación al ideal de vida que sostiene la jerarquía interior de los deseos humanos ${ }^{50}$. Es el sentido principal de la "trascendencia del bien" y la razón del porqué participar en su construcción es que se une de modo inseparable con la experiencia del propio crecimiento personal. La pluralidad de estos bienes no pierde la unidad interna que ahora está centrada en la vocación personal, la realidad que sirve de referencia a cualquier otro bien que se pone en juego ${ }^{51}$.

La vocación al amor implica a toda la persona en la construcción de su historia, y tiene como fin el don sincero de sí por el que el hombre encuentra su propia identidad, permite, pues, superar la separación entre individuo y comunidad en cuanto es llamada a formar una comunión de personas ${ }^{52}$. Por eso, el bien, incluso en la dinámica amorosa, es el fundamento de las relaciones humanas que, precisamente por esto, no son arbitrarias, sino que obedecen, en último término, a la lógica dirigida a realizar un bien mayor, como es el bien de la comunión. En cualquier comunión se realiza el bien original de la "communio personarum" en cuanto tal, que se explicita mediante el mismo bien comunicado que constituye la razón de las relaciones que dan vida a tal comunión. La comunión nace de un primer don compartido, pero requiere la acción de las personas implicadas para hacerlo crecer.

Destaca así la necesidad de la comunión de personas para poder hablar de un auténtico «bien de la persona» para distinguirlo de «los bienes para la persona ${ }^{53}$, distinción que quiere salir al paso de la diferencia entre bondad (goodness) de la persona y la rectitud (rightness) de la acción ${ }^{54}$, que es un

\footnotetext{
${ }^{50}$ Un ejemplo son los «hiperbienes» que defiende $\mathrm{CH}$. TAYLOR, Fuentes del yo. La construcción de la identidad moderna, Paidós, Barcelona 2012.

${ }^{51}$ Cf. J.J. PÉreZ-SoBA, Amor, justicia y caridad, Eunsa, Pamplona 2011, 126 y ss.

${ }^{52}$ Cf. J.J. PÉREZ-SOBA, El corazón de la familia, o.c., 315-316; ID., La pregunta por la perso$n a$, o.c., 252; F. Botturi, C. Vigna (eds.), Affetti e legami, Vita e Pensiero, Milano 2004. Como decía Aristóteles, «el hombre feliz necesita amigos»: ARISTÓTELES, Ética a Nicómaco, 1. 9, c. 9 (1169b22); SANTO TOMÁs DE AQuino, STh, I-II, q. 4, a. 8.

${ }^{53}$ Distinción que aparece en: JUAN PABlo II, carta enc. Veritatis splendor, 79. La analiza: L. Melina, Participar en las virtudes de Cristo, Cristiandad, Madrid 2004, 102-120.

${ }^{54} \mathrm{La}$ distinción entre goodness y rightness abandona el ámbito privado de la conciencia (el
} 
modo de subjetivizar el bien y de relativizar el valor de la acción. Por bien de la persona se entiende el bien moral que la persona encuentra en su acción en la medida en que esta acción lo realiza en cuanto persona, es decir, la sola inclinación de los deseos, o el orden que la razón puede poner en ellos, no es suficiente para poder determinar de un modo adecuado la experiencia moral del bien que perfecciona a la persona en cuanto tal. Necesita una idea de la vida como un todo, una vida lograda ${ }^{55}$, porque «el deseo del hombre solo puede permanecer abierto hacia ese fin, pues, en último término, no puede ser una acción del hombre, solo puede ser un don» ${ }^{56}$. Así pues, el bien de la persona se ha de dar en su acción pero permanece abierto a una medida que necesariamente va más allá de lo que el hombre puede actuar.

La vida plena solo se puede alcanzar en la comunión de personas, por eso, la comunicación en el bien adquiere un valor originariamente mo$\mathrm{ral}^{57}$, que remite a una acción primera de carácter creativo, de este modo se supera el sentido naturalista de intentar definir el bien sólo desde la apetibilidad y se abre a un sentido propiamente personal de bien: "el bien de la persona" ${ }^{\text {"5 }}$. Cada hombre nace, vive, se desarrolla y discierne su vida en torno a esta presencia activa de lo bueno, aunque no siempre lo sepa aceptar y hacerlo guía de su propia vida. En consecuencia, se ha de hablar de unos "bienes para la persona" que son necesarios para poder determinar con propiedad el "bien de la persona". Aquí aparece en toda su singularidad la relación "hombre y mujer" y destaca la correlación entre ambos como una verdad que no se descubre si se los separa y se los

propio del goodness) a un "sentido moral" comprendido de forma emotivista, mientras el segundo, el público de la razón (el rightness), queda sometido a un racionalismo que se reinterpreta teleológicamente. La distinción procede de: W.D. Ross, The Right and the Good, Hackett Pub.Co., Indianapolis 1988 (orig. Oxford 1930), aunque el principio de la distinción remite a: G.E. MoOre, Principia Ethica, Cambridge 1903. Cf. J.J. PÉrEz-SoBA, El corazón de la familia, o.c., 238.

${ }^{55} \mathrm{G}$. ABBÀ, Felicidad, vida buena y virtud, Einsa, Barcelona 1992.

${ }^{56}$ J.J. PÉREZ-SOBA, «La familia, bien de la persona y bien común», o.c., 39.

${ }^{57}$ Es lo que sostiene: I. MuRdOCH, The Sovereignty of Good, Routledge, London-New York 1989.

${ }^{58}$ Cf. L. MeLInA, J.J. PÉREZ-SobA (eds.), Il bene e la persona nell'agire, Lateran University Press, Roma 2002. 
considera aisladamente ${ }^{59}$. Se puede decir, entonces que «el hombre ha llegado a ser "imagen y semejanza" de Dios no solamente a través de la propia humanidad, sino también a través de la comunión de las personas, que el hombre y la mujer forman desde el inicio» ${ }^{60}$. En la comunión de personas la verdad inicial de la palabra expresa toda su bondad. Solo así se comprende el muy bueno que califica la aprobación divina de la existencia del hombre y su llamada a ser ${ }^{61}$. Es el bien de la trascendencia que aparece ya en la complementariedad de los $\operatorname{sexos}^{62}$.

Así, en una unión cada persona se enriquece por la aportación de la diferencia en el bien común que los une. Es desde lo concreto personal como el hombre se abre de hecho a lo universal. Por eso, mientras que la idea igualitarista es refractaria a la realidad familiar, el paradigma de la unión en la diferencia es, en primer lugar, el matrimonio y, luego, la familia ${ }^{63}$.

La singularidad del modo en el que se manifiesta el bien de la vida es paradigmática precisamente porque nos muestra como el hecho de introducir la cuestión del bien en las relaciones sociales puede modificar muchas ideas preconcebidas que, en el fondo, son reduccionistas y perjudiciales para la sociedad $^{64}$. Que la vida humana sea "siempre un bien", es inseparable de su

${ }^{59}$ Cf. F. Botturi, «Il bene della relazione e i beni della persona», en L. MelinA, J.J. PÉREZSoBA (eds.), Il bene della persona nell'agire, LUP, Roma 2002, 161-184.

${ }^{60}$ JUAN PABLO II, Hombre y mujer lo creó. Catequesis sobre el amor humano, Cristiandad, Madrid $2010^{2}$, cat. IX.

${ }^{61}$ Para poder hablar del bien como guía de la vida humana es necesario volver a un sentido fuerte de la creación: el bien presente en la creación — "vio Dios que era bueno" (Gn 1, 4, $10,12,18,21,25)$ - está ligado a su momento ontológico y es fundamento de un orden que tiene valor moral intrínseco para el hombre. «Y vio Dios que era muy bueno» (Gn 1, 31). El bien de cada cosa apunta más allá de ella misma, a un Bien del que todo procede y que las trasciende y las une en un destino. El Bien primero es también el fin último y común a todo lo creado. Lo analiza: G.L. MÜLLER, «"Vio Dios cuanto había hecho y todo estaba muy bien”» (Gn 1, 31). La creación como comunicación en el bien», en J.J. PÉREZ-SOBA, J. LARRÚ, J. BALleSteros (eds.), Una ley de libertad para la vida del mundo. Actas del Congreso Internacional sobre la ley natural, Madrid 22-24 noviembre 2006, Public. Facultad de Teología "San Dámaso", Madrid 2007, 61-70.

${ }^{62}$ Cf. J.J. PÉrez-SoBA, El corazón de la familia, o.c., 247.

${ }^{63}$ Cf. L. Melina, «Actuar por el bien de la comunión», en L. Melina, J. Noriega, J.J. PÉReZSoBA, La plenitud del obrar cristiano, Palabra, Madrid 2001, 379-401.

${ }^{64}$ Cf. J.J. PÉREZ-SOBA, «L'amore come principio di conoscenza sociale: verso una nuova 
consideración como un don y del hecho de que incluya una lógica del amor que supera la del simple respeto. El bien es entonces una fuente de sentido, fundamental para las acciones humanas, y en particular para las relaciones sociales, en las cuales una colaboración entre los hombres verdaderamente auténtica implica la común participación en el sentido de la acción que se realiza. El primer elemento en juego en una verdadera unión entre los hombres es el sentido de la vida que se transmite ${ }^{65}$.

De aquí emerge el sentido auténtico del desarrollo unido intrínsecamente al de la vocación personal, que nos permite encontrar un fundamento nuevo que pone de manifiesto la emergencia del bien en la vida social. Partir de la racionalidad del bien como orientación en nuestras acciones y como motivación del amor es esencial para comprender su significado en el ámbito de la convivencia social. La comunicación del bien no solo significa una efectividad del bien que mueve al hombre, indica al mismo tiempo «la finalidad del bien como realmente común en una unidad de destino y, en cuanto comunicación, implica siempre una relación con la libertad de la que brota y de la cual el hombre participa. La comunión se realiza por medio de una acción común que requiere una reciprocidad aunque cabe en ella la asimetría» ${ }^{66}$. El amor revela el bien en cuanto comunicativo, no es un mero sentimiento que recluye a las personas en su propia vivencia emotiva sino un elemento dinámico que permite construir una vida ${ }^{67}$. En efecto, el bien llega a ser común en la medida en que es objeto de una acción que responde a su comunicabilidad potencial poniéndola en acto. El bien común no se define sin más por el objeto, sino por la acción que realizan juntos ${ }^{68}$. El bien de la acción no es una "cosa" que se elige sino una acción que perfecciona al que la realiza.

epistemologia», en J.J. PÉRez-SobA, M. MAgdič, (eds.), L’ Amore principio di vita sociale. "Caritas aedificat" (1 Cor 8, 1). Studi sulla persona e la familia - Atti 12, Cantagalli, Siena 2011, 53.

${ }^{65}$ Cf. V.E. FrankL, El hombre en busca de sentido. El análisis existencial y la conciencia espiritual del ser humano, Paidós, Barcelona 1999.

${ }^{66}$ J.J. PÉREZ-SOBA, «La familia, bien de la persona y bien común», o.c., 40.

${ }^{67}$ Cf. J. NoriegA, El destino del eros, Palabra, Madrid 2005, 109-113.

${ }^{68}$ Cf. L. Th. Somme, «L'agire umano nella prospettiva del bene commune», en J.J. PÉREZSoba, M. Magdič, (eds.), L' Amore principio di vita sociale. "Caritas aedificat" (1 Cor 8, 1), Studi sulla persona e la familia - Atti 12, Cantagalli, Siena 2011, 187-201. 
Esta realidad de la acción común es la que se planteó Karol Wojtyla en el cuarto capítulo de Persona y acción que denomina "participación" y que es esencial para comprender el sentido real del "bien común" 69 , como una realidad que mueva internamente las acciones de los hombres y conforma su vida. Así lo podemos ver en relación al matrimonio como el bien que sostiene la familia en los bienes que lo constituyen y lo identifican. La especificidad de cada bien permanece en su integridad, los distintos bienes no se confunden entre sí, el lenguaje del amor con su analogía intrínseca defiende los diferentes modos en los que estos bienes comunican a los hombres. Es muy distinto el bien propio de la comunidad familiar, del que se realiza por medio del trabajo abierto al ámbito social, de la participación política en medio de la sociedad.

La aportación esencial de esta aproximación al bien común consiste en que permite entender que cada comunidad humana tiene su propio bien común pero que estos no son incompatibles entre sí que la unidad de todos ellos se fundamenta en la vocación personal que se ha de comprender siempre en relación a cierto sentido del bien común como un valor universal. Hemos de introducirnos en el modo como el amor nos inserta en la construcción de las comuniones esenciales para la vida humana y la profunda unión que se realiza en entre ellas.

\section{EL MATRIMONIO Y LA FAMILIA: LA TRASCENDENCIA DEL BIEN COMÚN}

El auténtico bien común no puede comprenderse sin una comunicación en el bien que encuentra en la corporeidad un significado privilegiado ${ }^{70}$. Juan Pablo II, en las Catequesis sobre el amor humano, desarrolla su teología del

\footnotetext{
${ }^{69}$ Cf. K. Wojtyla, Persona y acción, Palabra, Madrid 2011.

${ }^{70}$ En relación a la familia: C. CAFFARRA, «Famiglia e bene comune». Prolusione per l'inaugurazione dell'Anno Academico 2006/2007 del Pontificio Istituto Giovanni Paolo II per Studi su Matrimonio e Famiglia, nel XXVI dalla Fondazione, Pontificia Università Lateranense, Città del Vaticano (24-10-2006) 5-14. Cf. L. MelinA, J.J. PÉreZ-SoBA (eds.), La soggettività morale del corpo, Cantagalli, Siena 2012, 39.
} 
cuerpo, recogida posteriormente por Benedicto $\mathrm{XVI}^{71}$. En el ser humano la corporeidad está al servicio de la verdad del amor, en cuanto revela el origen creatural del hombre, su llamada al don de sí, a entregarse en la diferencia sexual, y su capacidad de engendrar vida. De esta manera, el hombre descubre, en su propio cuerpo, un lenguaje que debe aprender a leer en la verdad que encierra y que lo relaciona con el Creador ${ }^{72}$.

En efecto, el cuerpo tiene un lenguaje propio que expresa que el hombre no es un ser aislado, recibe su identidad en el encuentro y relación con los otros ${ }^{73}$. En primer lugar, el cuerpo tiene un significado filial, porque representa la relación del hombre con Dios; en segundo lugar, el cuerpo es nupcial, porque en él se manifiesta el amor entre el hombre y la mujer en su ser masculino y femenino, el cuerpo expresa la vocación del ser humano a convertirse en esposo; en tercer lugar, tiene un significado procreativo, porque la unión de los esposos se abre al don de la vida. Por tanto, la vocación y el destino de la persona humana - llamada a ser hijo, esposo y padre- está inscrita en su cuerpo. El cuerpo hace visible y eficaz el proyecto de comunión, su lenguaje es el lenguaje del amor: los cuerpos de los esposos, donde se siente la llamada a ser una carne, constituyen un principio de comprensión de la dimensión comunional del cuerpo y su significado de fecundidad. Tal llamada, además, está unida al «dominio del mundo» $(\mathrm{Gn}, 1,28)$ y permanece entonces abierta a las demás sociedades humanas que se definen por los bienes comunes que se ponen en juego.

Esta posibilidad de comunicación es la que permite hablar de la existencia de una verdad del bien. No cualquier acción humana es capaz de construir una comunión de personas, para ello debe saber descubrir la racionalidad de los distintos bienes y la libre construcción de las propias vidas. Así lo

${ }^{71}$ Cf. Deus caritas est ((25-XII-2005); C.A., Anderson, J. Granados, Llamados al amor. Teología del cuerpo en Juan Pablo II, Monte Carmelo, Burgos 2011 (original: Called to Love: Approaching John Paul II's Theology of the Body, Doubleday, New York 2009).

72 JUAN PABLO II, Hombre y mujer lo creó. Catequesis sobre el amor humano, Cristiandad, Madrid $2010^{2}$.

${ }^{73}$ Cf. C.A. Anderson, J. Granados, Llamados al amor. Teología del cuerpo en Juan Pablo II, Monte Carmelo, Burgos 2011, 156. 
podemos ver en relación al matrimonio, el bien que sostiene la familia y los bienes que lo constituyen y lo identifican.

\section{El bien común de los esposos}

En el matrimonio el primer bien es el de la complementariedad del hombre y la mujer ${ }^{74}$, que se da en la diferencia sexual como una llamada que tiene distintos niveles: físico sexual, psicológico, personal, y espiritual. Constituyen unos fines necesarios para cooperar en la construcción de la comunión; la unidad de todos ellos en la configuración de una vida capaz de ser entregada es la obra de la virtud de la castidad ${ }^{75}$. De esta manera, el matrimonio crea una comunión de personas que es, en sí misma, el verdadero bien común de los esposos, como señala Juan Pablo II en la Carta a las familias: «El consentimiento matrimonial define y hace estable el bien que es común al matrimonio y a la familia. "Te quiero a ti, ... como esposa - como esposo- y me entrego a ti, y prometo serte fiel en las alegrías y en las penas, en la salud y en la enfermedad, todos los días de mi vida" [...] Las palabras del consentimiento matrimonial definen lo que constituye el bien común de los esposos [...] el amor, la fidelidad, la honra, la duración de su unión hasta la muerte [...] El bien común, por su naturaleza, a la vez que une a las personas, asegura el verdadero bien de cada una ${ }^{76}$.

En el caso de los esposos, el bien común no se opone al interés de cada uno, al contrario, su comunión funda todo lo que tienen y son. Su unión misma - su bien común - es el fundamento de todo otro posible bien. Como consecuencia, la vida en común de la pareja no les priva de su libertad individual. La libertad de cada esposo no se siente amenazada por la presencia del otro ni de su mutua unión, sino que nace precisamente de su encuentro, por eso, la relación matrimonial permite a los esposos entender de forma

\footnotetext{
${ }^{74}$ Cf. CONGREgación PARA la Doctrina De LA Fe, Carta a los obispos de la Iglesia católica sobre la colaboración entre el hombre y la mujer en la Iglesia y en el mundo (31-V-2004).

${ }^{75}$ Cf. L. MelinA, «La castidad conyugal, virtud del amor verdadero», en L. MelinA, J. NoRIEGA, J.J. PÉREZ-SOBA, Una luz para el obrar. Experiencia moral, caridad y acción cristiana, Palabra, Madrid 2006, 257-269.

${ }^{76}$ JuAn PABLO II, Carta a las familias, 10
} 
distinta toda su vida en sociedad ${ }^{77}$. El fin de la libertad que descubre su verdad plena es entonces como ya lo recuerda Veritatis splendor, la comunión de personas ${ }^{78}$.

El "nosotros" realizado en el matrimonio es una disponibilidad a un "nosotros" más amplio, el familiar, y el camino para que cualquier otro "nosotros" no pierda su contenido humano ${ }^{79}$. Reconocer el don de la vida, señala como solo puede llegar a plenitud no por la satisfacción sino al darse ${ }^{80}$.

\section{Los hijos, bien común de la familia y de la sociedad}

La participación de los esposos en el bien común del matrimonio llega a plenitud con el nacimiento de los hijos, que transforma la «comunión conyugal en una comunidad de generaciones» ${ }^{81}$. Entra ahora en juego una nueva dimensión del bien común: la comunión de personas (marido y mujer) se expande en la comunidad del padre, madre e hijos $^{82}$. El bien de los esposos, que lo es de cada uno, deberá ser también el bien de los hijos, para ponerlo en evidencia la Iglesia les pregunta si están dispuestos a recibir y educar cristianamente a los hijos que Dios les conceda: «¿Estáis dispuestos a recibir de Dios responsable y amorosamente los hijos, y a educarlos...?» ${ }^{83}$. La pregunta se refiere al bien común del futuro núcleo familiar, teniendo presente la genealogía de las personas, que está inscrita en la constitución misma del matrimonio y de la familia.

En el recién nacido se realiza el bien común de la familia: «¿No es quizás

\footnotetext{
77 Cf. C. CAFFARRA, «Famiglia e bene comune». Prolusione per l'inaugurazione dell'Anno Academico 2006/2007 del Pontificio Istituto Giovanni Paolo II per Studi su Matrimonio e Famiglia, nel XXVI dalla Fondazione, Pontificia Università Lateranense, Città del Vaticano (24-10-2006) 5-14. S. Zamagni, Por una economía del bien común, Ciudad Nueva, Madrid 2012, 236 (original: L'economia del bene comune, Città Nuova Editrice, Roma 2008).

${ }^{78}$ Cfr. JuAn PABLO II, Veritatis splendor, n. 86.

${ }^{79} \mathrm{Cf}$. JuAn Pablo II, Carta a las familias, 8, 10.

${ }^{80} \mathrm{Cf}$. JUAN PABLO II, carta enc. Evangelium vitae, 49.

${ }^{81}$ JuAn Pablo II, Carta a las familias, 10.

${ }^{82}$ Cf. Juan Pablo II, Carta a las familias, 7.

${ }^{83}$ Ritual del matrimonio, Escrutinio, 93.
} 
[el hijo] una "partícula" de aquel bien común sin el cual las comunidades humanas se disgregan y corren el riesgo de desaparecer? ¿Cómo negarlo? El niño hace de sí mismo un don a los hermanos, hermanas, padres, a toda la familia [...] iSí, el hombre es un bien común!: bien común de la familia y de la humanidad, de cada grupo y de las múltiples estructuras sociales»» ${ }^{84}$. Por tanto, la familia no es una comunión «cerrada» o excluyente de un tercero como es la matrimonial, sino radicalmente «abierta» $\mathrm{y}$, por eso mismo, realiza la verdad completa del matrimonio.

El bien individual de cada uno de los esposos e hijos y el bien de la comunidad, está así en una relación intrínseca porque el bien individual solo se alcanza a verlo y justificarlo humanamente en relación al bien de la comunidad. Que un hombre o mujer se pregunten por "su bien" equivale a preguntarse por "nuestro bien". De esta forma, perseguir "mi bien" equivale a perseguir "nuestro bien", el bien de todos aquellos que participan en esa relación, el bien del matrimonio, el bien de la familia. Con ello se aprecia cómo es posible superar una concepción individualista del matrimonio y la familia basada simplemente en una autorrealización personal, en la que se ve el bien común desde una perspectiva instrumental.

Así pues, la familia, nacida de la entrega común de los esposos, se realiza en la aceptación del don de los hijos en una comunidad familiar ${ }^{85}$, posee una específica y original dimensión social, en cuanto lugar primario de las relaciones interpersonales, célula vital de la sociedad, titular de derechos propios y origina$\operatorname{rios}^{86}$. Por eso Juan Pablo II pudo hablar de la familia como la más fundamental «estructura de la ecología humana» ${ }^{87}$, en la que aprendemos algo esencial para el bien común. La familia, con un valor en sí misma por ser comunidad de vida y amor, enriquece además a las otras comunidades con la aportación libre de sus miembros. En ella se inculcan los valores morales, se transmite el patrimonio espiritual y cultural, y se aprenden las responsabilidades sociales ${ }^{88}$. Por eso la

\footnotetext{
${ }^{84}$ JuAn PABlo II, Carta a las familias, 11.

${ }^{85}$ Concilio Vaticano II, Const. past. Gaudium et spes, 48.

${ }^{86}$ JuAn PABLO II, Carta a las familias, 7.

${ }^{87}$ JuAn PABLO, Carta enc. Centesimus annus, 39.

${ }^{88}$ Catecismo de la Iglesia Católica, 2224.
} 
familia es el fundamento de la sociedad ${ }^{89}$. Todo ello hace que la familia deba ser reconocida como un verdadero sujeto, capaz de construir, de dialogar, de aportar, de exigir su reconocimiento en relación al bien común de la sociedad ${ }^{90}$. El reconocimiento de la subjetividad propia de la familia ha sido uno de los puntos clave en los que ha insistido Juan Pablo II, y que está subrayado en la Familiaris consortio $^{91}$. La familia se constituye de esta forma como algo que precede la sociedad misma y la genera, no solamente porque aporte los miembros que la componen sino porque hace posible el fundamento de relaciones que la constituyen al favorecer la formación de diversas células familiares que requieren todo un conjunto de nuevas relaciones ${ }^{92}$.

Juan Pablo II nos ofrece una reflexión muy profunda y original sobre el bien común en la Carta a las familias ${ }^{93}$. No se trata solo de un bien cuya responsabilidad ha sido delegada a quien gobierna. La novedad consiste en el hecho de que el bien común se observa a la luz de aquel bien que es la comunión misma, la cual une a las personas entre $\mathrm{si}^{94}$. Existe un bien común porque la comunión une entre sí a los diversos miembros de la familia. Y la familia surge como una escuela para comprender y vivir este bien común. Si los esposos tienen un bien común, no es únicamente porque comparten sus bienes individuales, sino más bien porque se han transformado en un sujeto nuevo, en una comunión de personas, de tal manera que todo aquello que ahora tienen, les pertenece a ellos de un modo nuevo, con un bien común. No tienen ya dos proyectos de vida sino uno solo; los bienes que comparten y que los unen, se funda sobre su bien relacional $^{95}$, que hace de sus vidas una sola y única vida.

${ }^{89}$ Cf. Concilio Vaticano II, Const. past. Gaudium et spes, 52; Juan Pablo II, Exh. ap. Christifideles laici, 40.

${ }^{90}$ Cf. Juan Pablo II, carta enc. Centesimus annus, 13.

${ }^{91}$ Cf. Juan Pablo II, Carta a las familias, 17; Exh. ap. Familiaris consortio, 42, 43, 72.

92 Cf. J.J. PÉREZ-SOBA, «El amor y su relevancia social», en Teología y Catequesis no 114 (2010) 59-89.

93 JuAn PABlo II, Carta a las familias, 12 (2-II-1994); cf. L. MelinA, «La familia y el bien común de la sociedad», conferencia pronunciada en la inauguración del año académico del Instituto Juan Pablo II para la Familia, Sección mexicana, 26 octubre 2011, en Alpha Omega, XV, n. 1, 2012, 47-55.

${ }^{94}$ L. MelinA, «La familia y el bien común de la sociedad», o.c., 49.

${ }^{95}$ Cf. P. DonAti, La familia como raíz de la sociedad, BAC, Madrid 2013. 
Esencial para esta nueva visión del bien común es el nacimiento del hijo. Se ve de esta manera la importancia que Juan Pablo II atribuye a la paternidad y a la maternidad como primera forma de abrir la familia más allá de sí misma $^{96}$. De hecho, el bien que el niño representa para el padre y para la madre es el ejemplo más claro de un bien común, el bien que ha nacido de la unión entre ellos y que ahora los une de un modo aun más estrecho. Se puede comprender de esta manera que el verdadero bien común de la sociedad es la persona, como lo destaca Benedicto $\mathrm{XVI}^{97}$.

Se obtienen así los principios fundamentales para la vida social. La libertad no es ya vista como un simple ejercicio de autonomía, al contrario, la libertad se hace posible gracias a la presencia del otro, desde el momento que debe entenderse como una libertad para el don. El hombre es libre no porque no tenga vínculos, sino al contrario, porque pertenece a una familia, a una comunidad que lo acoge y a la cual puede donarse. Es una libertad que construye la ciudad común no a partir del miedo al conflicto sino por el deseo de consolidar las relaciones entre las personas.

Se evidencia, por tanto, la subjetividad de la familia. Esto significa que la familia es más que la suma de sus miembros. La comunión que los une hace surgir una novedad que enriquece a todos en el "nosotros" común. Cada uno de sus miembros es quien es, gracias a las relaciones que los unen entre sí. La cuestión reviste una importancia decisiva a la hora de desarrollar políticas a favor de la familia, como muestra la actual sociología de la familia ${ }^{98}$.

La familia no es sólo un elemento particular a defender y que puede traer ventajas a la vida social, sino una dimensión propia del vivir humano, con repercusiones también políticas y económicas. En la encíclica Caritas in

\footnotetext{
${ }^{96}$ Cf. JuAn PABlo II; Carta a las familias, 11.

${ }^{97}$ Benedicto XVI, Carta enc. Caritas y veritate, 51.

${ }^{98}$ A este respecto, véase: P. DONATI: «Ripensare i "diritti della familia" e le politiche familiari a trent'anni dalla Familiaris consortio», en Rivista Anthropotes. Il futuro di una via: la fecondità di Familiaris consortio 30 anni dopo, P.I. Giovanni Paolo II per Studi su Matrimonio e Famiglia, XXVIII/1, 2012, 161-205; ID., «L'amore come cura dei beni relazionali», en J.J. PÉrez-SobA, M. MAGdič, (eds.), L' Amore principio di vita sociale. "Caritas aedificat" (1 Cor 8, 1), Studi sulla persona e la familia - Atti 12, Cantagalli, Siena 2011, 139-185; ID., «Una nova mappa del bene comune: perché e como dobbiamo rifondare lo Stato sociale», in M. Simone (ed.), El bene comune oggi, Edizioni Dehoniane Bologna 2008, 211-248.
} 
veritate, Benedicto XVI ha confirmado la fecundidad de este enfoque, afirmando que la caridad es un principio no solo de las microrrelaciones (las que se establecen entre amigos o familiares) sino entre las macrorrelaciones (las del mundo de la política y de la economía) ${ }^{99}$. La Carta a las familias anticipaba ya esta idea al situar en la familia la raíz de la experiencia del bien común, que es el bien de la comunión de las personas ${ }^{100}$.

En la familia se aprende que el bien común es el bien propio de la comunión. Ésta no es el resultado de la suma de los esfuerzos individuales, sino el fruto de la reciprocidad del amor interpersonal. La comunión no es solamente un don que se recibe gratuitamente sino, al mismo tiempo, el fin último al que se ha de encaminar toda la vida social.

\section{ACTUAR POR EL BIEN DE LA COMUNIÓN}

Lo que está en juego en la convivencia humana no es la mera comunicación de bienes según la regla de la justicia formal (do ut des), sino la comunicación entre las personas que se acogen y entregan mutuamente a través de la mediación de los bienes para las personas ${ }^{101}$. De este modo, la centralidad del bien común sitúa las relaciones sociales en una perspectiva no simplemente contractual e individualista, sino comunitaria. Como recuerda Juan Pablo II en su primera encíclica, el bien común es inseparable de lo que denomina amor social ${ }^{102}$, un término que usó ya san Bernardo como extensión del amor a uno mismo ${ }^{103}$.

Nuestro autor nos muestra cómo es posible redefinir el bien común a partir de la experiencia primordial, la experiencia de que es bueno vivir en común con otros. El bien común, fundado en la naturaleza y dignidad de nues-

\footnotetext{
${ }^{99}$ Cf. Benedicto XVI, Carta enc. Caritas in veritate, 1-2.

${ }^{100}$ Cf. L. MelinA, «La familia y el bien común de la sociedad», o.c., 51; L. MelinA, G. GALLAZZI, La familia è ancora un affare?, SRI Group, Milano 2010.

${ }^{101}$ Sobre la noción de bien común en cuanto fin del Derecho: J. BARRACA, Pensar el Derecho. Curso de filosofía jurídica, Palabra, Madrid 2005, 156-158.

102 JuAn PABlo II, Redemptor hominis, 16.

103 SAn Bernardo, De diligendo Deo, 23, en: Opere di San Benardo, I: Trattati, Scriptorium Claravallense, Fondazione di Studi Cisterciensi, Milano 1984, 304.
} 
tro ser, tiene una evidente historicidad ${ }^{104}$, de ahí que nuestra sociedad no pueda eludir afrontar la cuestión de la fuente primordial del bien común, que ha de ser el fin de la convivencia civil, y no la libertad individual.

En toda comunión hay que tener en cuenta dos realidades fundamentales que nos permiten definir realmente lo que puede significar el bien común. Por una parte, contamos con los bienes que se comunican en la relación que por ellos se establece entre las personas: la intimidad corporal en el matrimonio, la convivencia y los bienes en la familia, la educación en un colegio, el trabajo en un taller, etc... Por otra parte, hemos de referirnos a la unión que se realiza entre las personas. Se establece una intimidad común, cuyo valor es específicamente intersubjetivo, y que es necesario para que pueda existir una comunión de personas.

En claro contraste con el individualismo de la libertad, la dinámica de la vocación al amor favorece el bien común. El binomio amor-comunión enmarca el misterio de la libertad y la sitúa siempre en un marco interpersonal que tiene su fundamento en Dios. La comunión no se reduce a un acuerdo exterior pues daría lugar solamente a una comunidad formal o institucional, en último término impersonal. Una verdadera comunidad vital de personas no se funda en el intercambio de cosas o sobre principios formales que regulan su distribución equitativa, sino sobre la apertura de las personas entre sí a la luz de un bien en el que pueden comunicar. La idea del "bien común" se hace así posible y fundante de una auténtica colaboración entre los hombres en la construcción de la sociedad ${ }^{105}$.

El amor revela el bien en cuanto comunicativo, tiene la capacidad de establecer vínculos entre los hombres a todos los niveles y constituye un auténtico fundamento para la sociedad; es el verdadero motor de las acciones humanas. La relación intrínseca entre amor y acción nos permite comprender

\footnotetext{
${ }^{104}$ Pontificio consejo, “Justicia y PAZ”, Compendio de Doctrina social de la Iglesia, Editrice Vaticana, Ciudad del Vaticano 2004, nn. 164-166.

${ }^{105}$ Cf. L. MelinA, «La reflexión sobre la "verdad del amor" como camino de plenitud humana: la tarea del Pontifico Instituto Juan Pablo II», II Semana Internacional de Estudio "La familia cristiana para la vida del mundo", Sacrofano, 20-24 de agosto de 2007.

Disponible en: https://es.scribd.com/document/46099926/Livio-Melina-Reflexion-sobre-laverdad-del-amor [consultado el 1 octubre 2020].
} 
mejor la vida social del hombre que se constituye y edifica mediante acciones. De ahí que la recuperación del concepto de bien común pasa por reconocer el valor moral del mismo. Si no se considera desde la perspectiva de la acción, el bien común será siempre visto como una mera suma de bienes materiales o de consumo, sin ningún contenido moral directo. Por ello, el mejor modo de recuperar esta dimensión es la dinámica del amor, puesto que el bien se introduce en la estructura amorosa en el ámbito de la relación interpersonal ${ }^{106}$. Porque los bienes básicos de una sociedad no son los bienes de consumo o productos, sino las acciones humanas que surgen de la cooperación entre los hombres, en virtud de su participación en un mismo fin. La vocación al bien común forma parte de la vocación al amor de todo ser humano. Esta experiencia de que vivir unidos es un bien anterior a cualquier beneficio utilitarista que nos pueda reportar, es vivida y aprendida en la familia fundada en el matrimonio.

Al desarrollar su teoría de la participación en Persona y acción ${ }^{107}$, Wojtyla analiza cuatro actitudes ante la vida en sociedad. Dos son incapaces de alimentar una sociedad verdaderamente humana: el conformismo no es auténtico porque implica abandonar la libertad. La no participación tampoco es auténtica, porque es solipsista. El desligarme de los "otros" da como resultado la debilitación del propio ser. La oposición (que podría llamarse resistencia) puede suponer un enfoque auténtico de la vida en sociedad, si implica resistencia ante costumbres o leyes injustas. Y la solidaridad, la principal actitud auténtica hacia la sociedad, en la que la libertad individual se utiliza para servir al bien común, y la comunidad sostienes y soporta a los individuos a medida que se desarrollan hasta adquirir verdadera madurez humana: «Es esta actitud - escribe - la que permite al hombre llegar a la plenitud personal al complementar a los otros» ${ }^{108}$.

${ }^{106}$ Cf. L. MELINA, J.J. PÉREZ-SobA, «La persona agisce nel bene: appetibilità, perfezione e comunicazione. Note introduttive», en L. Melina, J.J. PÉREZ-Soba (eds.), Il bene e la persona nell'agire, Lateran University Press, Roma 2002, 9-17; J.J. PÉREZ-SOBA, «L'amore come principio di conoscenza sociale: verso una nuova epistemologia», en J.J. PÉREZ-SOBA, M. MAGDič, (eds.), L'Amore principio di vita sociale. "Caritas aedificat" (1 Cor 8, 1), o.c., $29-67$.

${ }^{107}$ K. WoJTYLA, Persona y acción, Palabra, Madrid 2011.

${ }^{108}$ K. Wojtyla, Persona y acción, o.c., 406. 
Señala la insuficiencia de un bien común entendido de modo objetivo y material, insistiendo en la necesidad de atender al sentido subjetivo ${ }^{109}$, del mismo en torno a acciones comunes, en cuanto «principio de participación correcta, que hace posible que la persona que actúa junto con otras personas realice acciones auténticas y se autorrealice por medio de estas acciones» ${ }^{110}$. A través de esta distinción se actualiza e ilumina la prioridad del bien de la persona sobre los bienes para la persona; del ser y actuar sobre el tener; de la ética sobre la técni$\mathrm{ca}^{111}$. Podremos así trazar un dinamismo del bien en cuanto común que, de por sí, indica las líneas directrices que constituyen la estructura social. El motivo fundamental es que el bien es la razón fundamental del movimiento de la voluntad humana. De hecho, los principales bienes de la vida son dones comunes recibidos por todos, y se transforman en la base misma de las comunidades que se pueden definir de algún modo como "naturales".

En esta primera comunicación de bienes se articula una nueva racionalidad social estrechamente ligada a la del bien, que exige su integración mediante la virtud ${ }^{12}$. Gracias a su inteligencia el hombre puede descubrir el bien que comparte con otros hombres como un fin de sus actos. Ello permite configurar un verdadero y propio "ethos" social, que comprende una serie de preferencias, de relaciones y motivaciones que se transmiten a través de la cultura, y que son fundamentales para la sociedad en su conjunto. Por tanto, es erróneo considerar el ámbito social como un mero sistema de acuerdos garantizados por un sistema procedimental. Cuando la realidad social se separa de una idea real y fuerte de bien, se produce una desmoralización de la misma, ya que se comienzan a considerar negociables incluso los bienes excelentes que deberían ser los pilares de la convivencia ${ }^{113}$.

${ }^{109}$ K. WOJTYLA, Persona y acción, o.c., 401: «[...] el objetivo de la actuación común, cuando se entiende en sentido puramente objetivo y "material", aunque incluye algunos elementos del bien común y hace referencia a él, no puede nunca constituirlo plena y completamente».

${ }^{110}$ K. WOJTYLA, Persona y acción, o.c., 402.

${ }^{111}$ Cf. J.J. PÉrez-SobA, “La persona y el bien”, en L. Melina, J. J. Pérez SobA, J. Noriega, La plenitud del obrar cristiano: Dinámica de la acción y perspectiva teológica de la moral, Madrid 2001, 303-306.

${ }^{112}$ Cf. P. DonAti, La familia como raíz de la sociedad, BAC, Madrid 2013; J.J. PÉREZ-SoBA, Amor, justicia y caridad, EUNSA, Pamplona 2011, 99.

${ }^{113}$ Cf. Ch. TAYLOR, Sources of the Self. The Making of the Modern Identity, Harvard Univer- 
Afirmar la dimensión social del amor como constitución primigenia de la sociedad nos permite redescubrir el modo en el que la dimensión moral está ligada a la estructura social, ya que está constituida por bienes comunes que son acciones humanas que "edifican" la persona y la sociedad. La función de la comunidad política, por tanto, no es de mera distribución de bienes, sino de desarrollo de un "cuerpo social" que implica una creatividad de los hombres respecto de los bienes humanos que son históricos y culturales.

El amor nos permite tener una mejor percepción del bien común que da vida a la sociedad y constituye su fin. Porque el amor no es un objeto que se pueda contemplar o fin para elegir, sino que es el verdadero motor de todas las acciones humanas. Esta relación intrínseca entre amor y acción es fundamental para una adecuada comprensión de la vida social del hombre que se constituye y "edifica" mediante tales acciones. Las tres moradas que el hombre edifica en su vida: el hogar, la ciudad y el templo significan la esfera de la intimidad, la de la sociabilidad y la de la trascendencia. Estos tres sentidos no se dan fragmentados sino que se interrelacionan íntimamente en la vida de los hombres de una forma activa, pues se trata de introducirse en el cultivo de una familia, el despliegue de una cultura y el culto a Dios. Es esencial comprender la integración de estos sentidos ya que vivimos en una cultura que sistemáticamente ha querido olvidar la trascendencia ${ }^{114}$.

La verdad de la vida social no se puede reducir a un modo de colaboración instrumental que nos ayude a conseguir cosas y bienes que solos no podemos, superando así las propias carencias. El fin de la vida social no está definido tan solo por los bienes para la persona que esa colaboración pueda realizar. No es una cuestión de simple eficacia lo que está al origen de la vida social, sino una vocación, la llamada a una plenitud que solos no podemos alcanzar, que nos interpela e invita a construir una comunión, en la que se realiza el bien de la persona ${ }^{115}$. De este modo, el bien de la persona puede ser realizado a través del libre ejercicio de la libertad gracias a la orientación

sity Press, Cambridge, MA 1989 (trad. esp. Fuentes del yo. La construcción de la identidad moderna, Paidós, Barcelona 2012²).

114 J.J. PÉrez-SobA, O. Gotia (eds.), Il cammino della vita: l'educazione, una sfida per la morale, Lateran University Press, "Lezioni e dispense", Roma 2007, 50.

${ }^{115}$ Cf. L. Melina, Cristo e il dinamismo dell'agire, Roma 2001, 37-51. 
de la intencionalidad al bien de la comunión, a un actuar que hace posible la comunicación en el bien y la comunión entre las personas. Aquí es donde se ilumina la verdad del bien común, comprendiéndolo a la luz del bien de la comunión.

«No te dejes vencer por el mal, antes bien, vence al mal con el bien» (Rm 12,21 ), este pasaje bíblico resume muy bien la grandeza y santidad de la vida de san Juan Pablo II, está presente en todo su magisterio, especialmente en sus tres primeras encíclicas (Redemptor hominis, Dives in misericordia, Dominum et vivificantem) y en sus encíclicas sobre la justicia y el orden social (Laborem exercens, Sollicitudo rei socialis, Centesimus annus). Fue también el lema que escogió para la última Jornada Mundial de la paz de su pontificado: «Ningún hombre, ninguna mujer de buena voluntad puede eximirse del esfuerzo en la lucha para vencer al mal con el bien. Es una lucha que se combate eficazmente sólo con las armas del amor. Cuando el bien vence al mal, reina el amor y donde reina el amor reina la paz. Es la enseñanza del Evangelio, recordada por el Concilio Vaticano II: "La ley fundamental de la perfección humana, y por ello de la transformación del mundo, es el mandamiento nuevo del amor"» ${ }^{116}$.

Para vencer el mal con el bien, hay que tener en cuenta el bien común ${ }^{117} \mathrm{y}$ sus consecuencias sociales y políticas. «¿Acaso puede realizarse plenamente la persona prescindiendo de su naturaleza social, es decir, de su ser con y para los otros? El bien común le concierne muy directamente. Concierne a todas las formas en que se realiza su carácter social: la familia, los grupos, las asociaciones, las ciudades, las regiones, los Estados, las comunidades de pueblos y de Naciones. De alguna manera, todos están implicados en el trabajo por el bien común, en la búsqueda constante del bien ajeno como si fuera el propio» ${ }^{118}$.

\footnotetext{
116 Juan Pablo II, Jornada Mundial de la paz (1 enero 2005), 12; la cita es de Cons. past. Gaudium et spes, 38.

${ }^{117}$ Concilio VATiCAno II, Cons. past. Gaudium et spes, 26: «el bien común es el conjunto de aquellas condiciones de vida social que permiten a los grupos y a cada uno de sus miembros conseguir más plena y fácilmente su propia perfección».

${ }^{118}$ JuAn PABLo II, Mensaje para la Jornada Mundial de la paz (1 enero 2005), 5.
} 
En definitiva, saber descubrir el bien común desde la perspectiva del amor es un modo de mostrar la necesaria referencia al bien pues ningún hombre puede considerarse indiferente ante el amor, como si fuese algo que no le afecta. Por el contrario, la identificación entre persona y amor, que ha sido una de las aportaciones del personalismo, tiene sin duda, una dimensión social en la cual la objetividad del bien es una base imprescindible para definir las relaciones sociales fundamentales ${ }^{119}$. Por eso hemos de volver a la vocación al amor como la que conserva últimamente el sentido real del bien común.

${ }^{119}$ Cf. L. Melina, J.J. PÉREZ-SobA, (eds.), Il bene e la persona nell'agire, Lateran University Press, Roma 2002. 